\title{
Preparation and Characterization of Microporous Activated Carbon From Oil Palm Shell by Physical Activation Using Purified Nitrogen
}

\author{
Allwar ${ }^{\mathrm{a}}$, Ahmad Md Noor ${ }^{\mathrm{b}}$, and Moh Asri Moh Nawi ${ }^{\mathrm{b}}$ \\ ${ }^{a}$ Jurusan Ilmu Kimia, Fakultas Matematika dan Ilmu Pengetahuan Alam, \\ Universitas Islam Indonesia, Indonesia \\ ${ }^{\mathrm{b}}$ School of Chemical Sciences Universiti Sains Malaysia (USM). 11800 Pulau Pinang, Malaysia \\ Corresponding author: e_allwar@yahoo.com
}

\begin{abstract}
Oil palm shell, a byproduct of palm oil industry was successfully used as a raw material for the production of highly porous activated carbons. Preparation of activated carbon was carried out by physical activation under nitrogen at various activation temperatures. The nitrogen isotherms show Type I characteristics of microporous activated carbon. The maximum surface areas obtained at $900^{\circ} \mathrm{C}$ was $936 \mathrm{~m}^{2} \mathrm{~g}^{-1}$. The morphology structure of the activated carbon indicated the existence of the porosities with different size pores.

Keywords: Oil palm shell, Micropores, Physical activation, Nitrogen adsorption-desorption isotherm

ABSTRAK

Tempurung kelapa sawit, hasil samping dari industri minyak kelapa sawit telah berhasil di gunakan sebagai bahan baku untuk membuat arang aktif yang mempunyai banyak pori-pori. Proses pembuatan dilakukan dengan cara aktifasi fisika dalam atmosfir nitrogen pada temperatur aktivasi yang berbeda. Isotherm nitrogen membuktikan bahwa arang aktif mempunyai Type I, untuk karakteristik arang aktif miropori. Hasil maksimum luar permukaan di peroleh $936 \mathrm{~m}^{2} \mathrm{~g}^{-1}$ pada temperature $900^{\circ} \mathrm{C}$. Struktur permukaan dari arang aktif membuktikan bahwa arang aktif mempunyai ukuran pori-pori yang berbeda.
\end{abstract}

Kata-kata kunci: Tempurung kelapa sawit, Mikropori, Aktivasi Fisika, Isoterm adsorpsi-desorpsi Nitrogen 